\title{
TaDAD2, a Negative Regulator of Programmed Cell Death, Is Important for the Interaction Between Wheat and the Stripe Rust Fungus
}

\author{
Xiaojie Wang, ${ }^{1}$ Chunlei Tang, ${ }^{2}$ Hongchang Zhang, ${ }^{2}$ Jin-Rong Xu, ${ }^{1,3}$ Bo Liu, ${ }^{1}$ Jie LV, ${ }^{1}$ Dejun Han, ${ }^{1}$ \\ Lili Huang, ${ }^{1}$ and Zhensheng Kang ${ }^{1}$ \\ ${ }^{1}$ College of Plant Protection and Shaanxi Key Laboratory of Molecular Biology for Agriculture, Northwest A\&F University, \\ Yangling, Shaanxi, 712100, P. R. China; ${ }^{2}$ College of Life Science, Northwest A\&F University, Yangling, Shaanxi, 712100, \\ P. R. China; ${ }^{3}$ Department of Botany and Plant Pathology, Purdue University, West Lafayette, IN 47907, U.S.A.
}

Submitted 6 June 2010. Accepted 23 August 2010.

\begin{abstract}
Defender against cell death $(D A D)$ genes are known to function as negative regulators of cell death in animals. In plants, DAD orthologs are conserved but their role in cell death regulation is not well understood. Here, we report the characterization of the $T a D A D 2$ gene in wheat. The predicted amino acid sequence of TaDAD2 contains typical structural features of DAD proteins, including a signal peptide, three transmembrane regions, and a subunit of oligosaccharyltransferase. Transcripts of $T a D A D 2$ were detected in wheat leaves, culms, roots, florets, and spikelets. The expression level of $T a D A D 2$ was reduced in the initial contact with the stripe rust fungus, subsequently induced and peaked at $18 \mathrm{~h}$ postinoculation (hpi), gradually reduced at 24 to $48 \mathrm{hpi}$, and restored to control level at 72 to 120 hpi. In addition, TaDAD2 exhibited positive transcriptional responses to abiotic stresses after the initial reduction at $1 \mathrm{hpi}$. Overexpression of $T a D A D 2$ in tobacco leaves inhibited cell death. Furthermore, knocking down TaDAD2 expression by virusinduced gene silencing enhanced the susceptibility of wheat cv. Suwon11 to avirulent race CYR23 and reduced necrotic area at the infection sites. These results indicate that $T a D A D 2$ may function as a suppressor of cell death in the early stages of wheat-stripe rust fungus interaction. However, it is dispensable for or plays an opposite role in hypersensitive response or cell death triggered by an avirulent race of stripe rust fungus at late-infection stages.
\end{abstract}

Programmed cell death (PCD) plays an important role in the growth and differentiation of multicellular organisms by removing unwanted or harmful cells (Geske and Gerschenson 2001; Ruf et al. 1999). A complex machinery of interconnected signal transduction pathways underlies the capability of cells to sacrifice themselves in response to a range of internal and external stimuli. In plants, the recognition of avirulence (AVR) products by corresponding resistance $(R)$ genes is often associated with hypersensitive response (HR), which is a rapid plant-initiated PCD (Heath 2000; Lam et al. 2001). HR as a form of PCD resulting from incompatible interactions is believed to help plants defend themselves against the invading pathogen by limiting its growth. One of the earliest events in

Corresponding author: Z. Kang; E-mail: kangzs@nwsuaf.edu.cn

* The $\boldsymbol{e}$-Xtra logo stands for "electronic extra" and indicates that two supplementary figures and one supplementary table are published online.
HR is the rapid accumulation of reactive oxygen species (ROS) and nitric oxide (NO) (Chandok et al. 2003; Keller et al. 1998). Both NO and ROS are components of a highly amplified and integrated defense system that involves the induction of salicylic acid (SA) accumulation, activation of ion fluxes, oxidative cross-linking of plant cell wall proteins, and changes in protein phosphorylation patterns, extracellular $\mathrm{pH}$, membrane potential, and the cytosolic $\mathrm{Ca}^{2+}$ level (Delledonne 2005; Gechev et al. 2006; Klessig et al. 2000; Mittler et al. 2004). These events trigger the expression of disease resistance mechanisms and result in the establishment of systemic acquired resistance (SAR), which provides resistance to a broad range of pathogens in distal plant tissues (Bolwell 1999; Yoshioka et al. 2009).

The main, characteristic morphological features of PCD in animals, which is often referred to as apoptosis, include cellular shrinkage, membrane blebbing, nuclear condensation, DNA fragmentation, and formation of apoptotic bodies (Higuchi 2003; Richberg et al. 1998). Many of these features also can be observed in plant PCD and used as markers of plant cell death (McCabe and Leaver 2000; McCabe et al. 1997).

In animal cells, the key proteases and specific regulatory proteins involved in PCD have been well characterized, including caspases, bcl-2, defender against apoptotic cell death 1 (DAD1), p53, c-myc, and fas (Kopitz et al. 2003; Mittapalli and Shukle 2008; O'Donnell et al. 2005; Pozo-Guisado et al. 2005; Ruf et al. 1999). To date, no homologues of animal caspase genes have been identified in plants despite the complete sequencing of Arabidopsis thaliana, rice, and other plant genomes. Bcl-family genes, such as Bcl-2 or Bax, also lack distinct homologues in plants, although transgenic expression of these genes can influence plant cell death (Lacomme and Cruz 1999; Mitsuhar et al. 1999). However, some of the suppressors of PCD have orthologous sequences in plants, such as $\mathrm{Bcl}-2$ associated athanogene $(B A G)$, defender against apoptotic death $(D A D)$, and Bax inhibitor $1(B I-1)$. These genes may be functionally related to plant PCD (Matsumura et al. 2003; Moharikar et al. 2007; Watanabe and Lam 2006) as the conserved negative regulators.

DAD proteins are well conserved from yeast to mammals. Most plants have two closely related paralogous $D A D$ genes. $D A D 1$ was first identified from a temperature-sensitive hamster cell line, tsBN7, that underwent apoptotic cell death when incubated at nonpermissive temperatures. Its orthologues have been identified as putative antiapoptosis genes in several distantly related organisms, including human, Caenorhabditis 
elegans, mouse, and pea (Brewster et al. 2000; Orzáez and Granell 1997; Sugimoto et al. 1995; Zhu et al. 2008). Because expression of some $D A D 1$ orthologues from plants, such as rice, could suppress apoptotic cell death in the dad-1 mutant line of hamster cells (Tanaka et al. 1997), these genes may play a role in negative regulation of plant cell death. However, to date, the exact function of $D A D$ genes in wheat or other monocots has not been directly characterized.

Stripe rust (or yellow rust), caused by Puccinia striiformis f. tritici Erikss., is a common and damaging disease of wheat (Triticum aestivum L.) worldwide. One effective disease control measure is the application of stripe-rust-resistant cultivars. To date, over 30 stripe rust resistance genes have been identified in wheat. The gene-for-gene resistance against $P$. striiformis f. tritici involves the death of infected plant cells within hours after initial contact with the pathogen. To determine molecular mechanisms involved in the wheat $-P$. striiformis f. tritici interaction, in this study, we isolated and characterized a wheat $D A D$ homologue, named $T a D A D 2$, that shares the highest similarity with barley $H v D A D 2$ (GenBank accession number Q9SME8). TaDAD2 was expressed in different plant tissues and its expression was induced in the late $P$. striiformis f. tritici infection stages. Expression of TaDAD2 in tobacco tissues suppressed Bax-induced PCD. Furthermore, knocking down TaDAD2 expression enhanced the susceptibility of wheat $\mathrm{cv}$. Suwon11 to an avirulent $P$. striiformis f. tritici strain and reduced necrotic area per infection site. These results indicate that $T a D A D 2$ may function as a suppressor of cell death in the early stages of the wheat- $P$. striiformis $\mathrm{f}$. tritici interaction but its role in HR-related cell death at late stages of $P$. striiformis $\mathrm{f}$. tritici infection may be different.

\section{RESULTS}

\section{The deduced amino acid sequence and} structural features of TaDAD2.

One cDNA clone from a cDNA library during early stages of wheat-P. striiformis f. tritici interactions (Ma et al. 2009) shared the highest homology with the barley $H v D A D 2$ gene (GenBank accession number Q9SME8). The sequence information of this subtraction clone was used to design primers for amplifying the genomic and cDNA fragments of the corresponding gene, which was named TaDAD2 in this study. Primers TaDAD2-S and TaDAD2-AS were used to amplify a portion of the TaDAD2 coding region. Both a 289-bp 5' rapid amplification of cDNA ends (RACE) and a 315-bp 3' RACE product were amplified and sequenced to obtain the upstream and downstream sequences of the TaDAD2 open reading frame (ORF). The assembled-full length TaDAD2 (GenBank accession number GU564291) cDNA sequence is 607 bp in length. The predicted ORF of TaDAD2 encodes a protein with 114 amino acid residues, which is highly similar (over 90\% identity) to its orthologues from other monocots (Fig. 1A). TaDAD2 shares its highest homology (96\% identity) with barley HvDAD2 (Fig. 1B). It also exhibits 78 and $43 \%$ sequence identity to Arabidopsis AtDAD1 and human HsDAD1, respectively. The primary structure of TaDAD2 contains three transmembrane regions ( 25 to 50,59 to 79 , and 93 to 113) and a subunit of oligosaccharyltransferase (11 to 114), which are conserved in DAD proteins from animals and plants.

Like AtDADl and its orthologues from monocots, the coding region of TaDAD2 (GenBank accession number GU564293) contains five exons. The order and approximate sizes of exons and introns are well conserved among $D A D$ genes from wheat, Arabidopsis, and other plants. As expected, the introns have lower sequence identity (18 to $32 \%$ ) than the exons in TaDAD2 and its orthologues.

\section{Transcription of TaDAD2 in wheat organs.}

To determine biological functions of the TaDAD2 gene in plant development, we examined its expression patterns in five different tissues by quantitative reverse-transcription polymerase chain reaction (qRT-PCR). Transcripts of TaDAD2 were detectable in all wheat tissues tested (Fig. 2A). In leaves, culms, and roots, transcripts of TaDAD2 were found at moderate abundance. The expression level of TaDAD2 in florets (at anthesis) and spikelets was approximately 50\% lower than in the other three tissues examined (Fig. 2A).

\section{Transcriptional responses of TaDAD2 to $P$. striiformis f. tritici infection and abiotic stress treatments.}

Wheat seedlings of cv. Suwon 11 were inoculated with race CYR23 (incompatible) or race CYR31 (compatible) of the stripe rust fungus. The abundance of $T a D A D 2$ transcripts in the inoculated leaves was evaluated by qRT-PCR. In leaves inoculated with race CYR23, the expression level of TaDAD2 was slightly downregulated by $12 \mathrm{~h}$ postinoculation (hpi) in comparison with that of time 0 control $(0 \mathrm{hpi})$. TaDAD2 expression was then induced and peaked at $18 \mathrm{hpi}$, and remained higher than the initial level (0 hpi) by $48 \mathrm{hpi}$. The expression level of $T a D A D 2$ was almost reduced to that of the time 0 control from 72 to 120 hpi (Fig. 2B). In leaves inoculated with virulent race CYR31, TaDAD2 transcription also was mildly reduced at $12 \mathrm{hpi}$ and peaked at $18 \mathrm{hpi}$. However, the induction of TaDAD2 expression in the compatible interaction was less than in the incompatible interaction at $18 \mathrm{hpi}$. In CYR31infected leaves, the expression of TaDAD2 was reduced to the time 0 control level at $24 \mathrm{hpi}$ (Fig. 2B).

We also assayed changes in TaDAD2 expression in responses to abiotic stresses. In general, the expression level of TaDAD2 was reduced as early as $1 \mathrm{~h}$ posttreatment (hpt), then induced at 3 to $6 \mathrm{hpt}$ but restored to the untreated level at 12 to $24 \mathrm{hpt}$ in wheat seedlings treated with wound, PEG6000, or $\mathrm{NaCl}$ (mimicking water-deficient or osmotic stress) (Fig. 3). However, the induction of TaDAD2 transcription was more substantial in PEG6000-treated seedlings (Fig. 3). Together, these results suggest a general role of $T a D A D 2$ in stress responses.

\section{Evidence for the involvement of TaDAD2 in suppressing cell death.}

To determine whether TaDAD2 could suppress PCD induced by the pro-apoptotic protein Bax, we used the doublebarreled attachment of the Bio-Rad Gene Gun as described (Dou et al. 2008) for co-bombardment assays. On tobacco (Nicotiana benthamiana) leaves co-bombarded with the empty vector pUC19 and $\beta$-glucuronidase (GUS) vectors, numerous blue spots were observed (Fig. 4A). Co-bombardment with the TaDAD2 and GUS vectors had no obvious effects on the number of blue spots formed on tobacco leaves (Fig. 4A; Table 1), indicating that $T a D A D 2$ had no effect on the transformation efficiency or transient expression of the GUS gene.

In contrast, compared with leaves bombarded with the GUS gene alone, the number of blue spots was reduced to approximately $25 \%$ (Fig. 4B; Table 1) on leaves co-bombarded with the GUS gene and a mouse Bax gene, which is known to trigger PCD in tobacco (Lacomme and Cruz 1999). These results are consistent with earlier publications (Mindrinos et al. 1994; Qutob et al. 2002) that the expression of Bax elicits PCD and eliminates tobacco cells expressing the GUS reporter gene. When TaDAD2 was co-bombarded with the Bax and GUS vectors, more than twofold more blue spots were observed on tobacco leaves (Fig. 4C; Table 1) than those only bombarded with the Bax and GUS vectors, indicating that presence of 
TaDAD2 increased the number of cells expressing the GUS gene. To further confirm this observation, we bombarded tobacco leaves with a mixture of pUCTaDAD2, pUCBax, and pUCGUS in the first barrel and a mixture of empty vector pUC19, pUCGUS, and pUCBax in the second barrel (Fig. 4D). The ratio of the logarithm of the blue spots formed on leaves bombarded with Bax and TaDAD2 to that with the empty vector and Bax was 2.13 (Table 1). Therefore, we con- clude that $T a D A D 2$ could partially suppress Bax-induced PCD in tobacco cells.

Suppression of TaDAD2 expression in wheat enhanced susceptibility to $P$. striiformis f. tritici infection.

To further characterize its function, the TaDAD2 gene was silenced with the Barley stripe mosaic virus (BSMV)-based

A

TaDAD2

MPKPAGDAKLLIQSITKAYAATPTNLKIIDLYVVFAVATALVQVVYMGIV

OsDAD1

ZmDAD1 MPRATSDAKLLIQSLGKAYAATPTNLKI IDLYVVFAVATAL IQVVYMGIV MPRATSDAKLLIQSLGKAYAATPTNLKIIDLYVGFAVATALIQVAYMGIV

HvDAD2 MPKAAGDAKLLIQSLNKAYAATPTNLKIIDLYVVFAVA TALVQVVYMGIV

HvDAD1

MPKAAGDAKLLIQSLNKAYAATPTNLKIIDLYVVEAVVTALIQVVYMGIV

TM II OT

TaDAD2

OSDAD1

ZmDAD1

HvDAD2

HvDAD1

GSFPENSFLSGVISCIGTAVIGVCIRIQVNKDNKEFKDLPPFRAFADFVI GSFPENSFISGVISCIGTAVIAVCIRIQVNKDNKEFKDLPPERAFADEVI

100 GSFPFNSFLSGVLSCIGTAVIAVCIRIQVNKDNKEFKDLPPERAFADFVI

100 GSFPENSFLSGVLSSIGTAVIGVCIRIQVNKDNKEFKDLPPERAFADFVI

100 GSFPFNSFLSGVLSCIGTAVIAVCHRIQVNKDNKEFKDIAPERAFADFVI

100

TMIII

TaDAD2

OT

OsDAD1

$\mathrm{ZmDAD} 1$

HvDAD2

HvDAD1
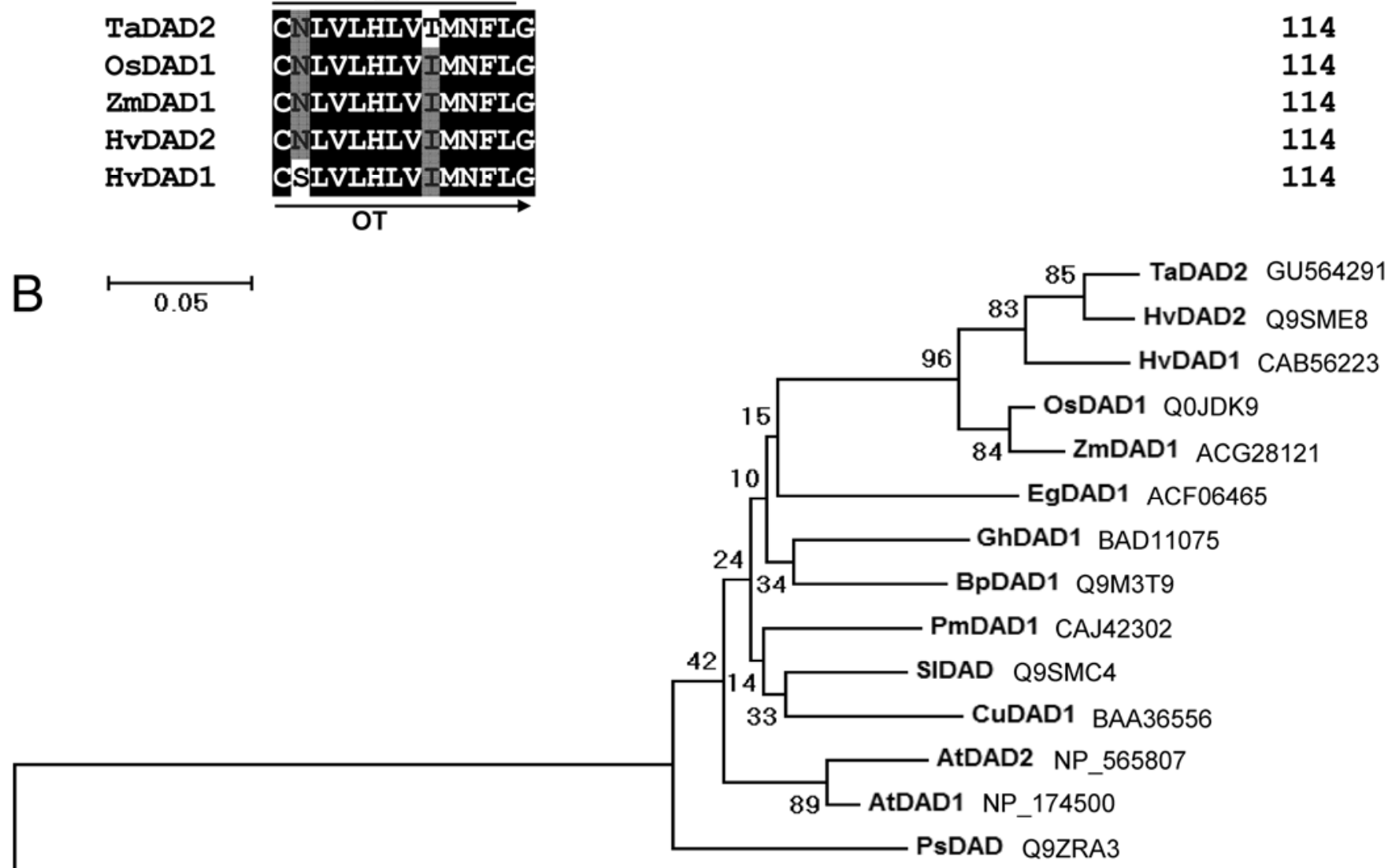

HsDAD1 AAH09798

Fig. 1. Sequence alignment and phylogenetic analysis of TaDAD2 and other defender against cell death (DAD) proteins. A, Amino acid sequence comparisons. Amino acid residues conserved in all five sequences are shaded in black. Residues shaded in light gray are conserved among four of the sequences. TM, transmembrane domain; OT, oligosaccharyltransferase domain. B, Representative phylogenetic tree of TaDAD2 and DAD family member proteins from rice (OsDAD1), maize (ZmDAD1), human (HsDAD1), Arabidopsis (AtDAD1, AtDAD2), Hordeum vulgare (HvDAD1, HvDAD2), Elaeis guineensis (EgDAD1), Citrus unshiu (CuDAD1), Betula pendula (BpDAD1), Pisum sativum (PsDAD), Gladiolus (GhDAD1), Plantago major (PmDAD1), and Solanum lycopersicum (SIDAD) constructed with the neighbor-joining method. GenBank accession numbers are provided after the gene names. HsDAD1 was used as the outgroup control. Bootstrap values shown were estimated based on 1,000 replications. 
virus-induced gene silencing (VIGS) system, which is an effective reverse genetics tool in barley and wheat (Holzberg et al. 2002; Scofield et al. 2005). We first tested the silencing of the wheat phytoene desaturase gene $(P D S)$ in cv. Suwon 11. On wheat seedlings inoculated with BSMV:TaPDSas on the second leaf, mild chlorotic mosaic symptoms became visible on the third leaf at 9 days postinoculation (dpi). Photobleaching symptoms were observed by $15 \mathrm{dpi}$ (Fig. 5A). Under the same conditions, wheat plants mock inoculated with sterile buffer developed normal leaves (Fig. 5A), indicating that silencing of TaPDS occurred specifically in BSMV:TaPDSasinfected plants.

We then infected seedlings of Suwon 11 with the recombinant BSMV:TaDAD2as virus that contains a 161-bp fragment amplified with primers TaDAD2_vigs_S and TaDAD2_vigs_ AS. These two primers are located in regions that are not conserved between TaDAD1 and TaDAD2 (Supplementary Fig. 2). The BSMV:TaDAD2as-inoculated plants also displayed mild chlorotic mosaic symptoms by 9 dpi but had no obvious defects in further leaf growth (Fig. 5A). The fourth leaves of wheat plants mock inoculated with buffer or infected with BSMV: $\gamma$ and BSMV:TaDAD2as were then inoculated with urediospores of CYR23 or CYR31. Conspicuous HR was elicited by CYR23 on leaves preinfected with BSMV: $\gamma$ or BSMV:

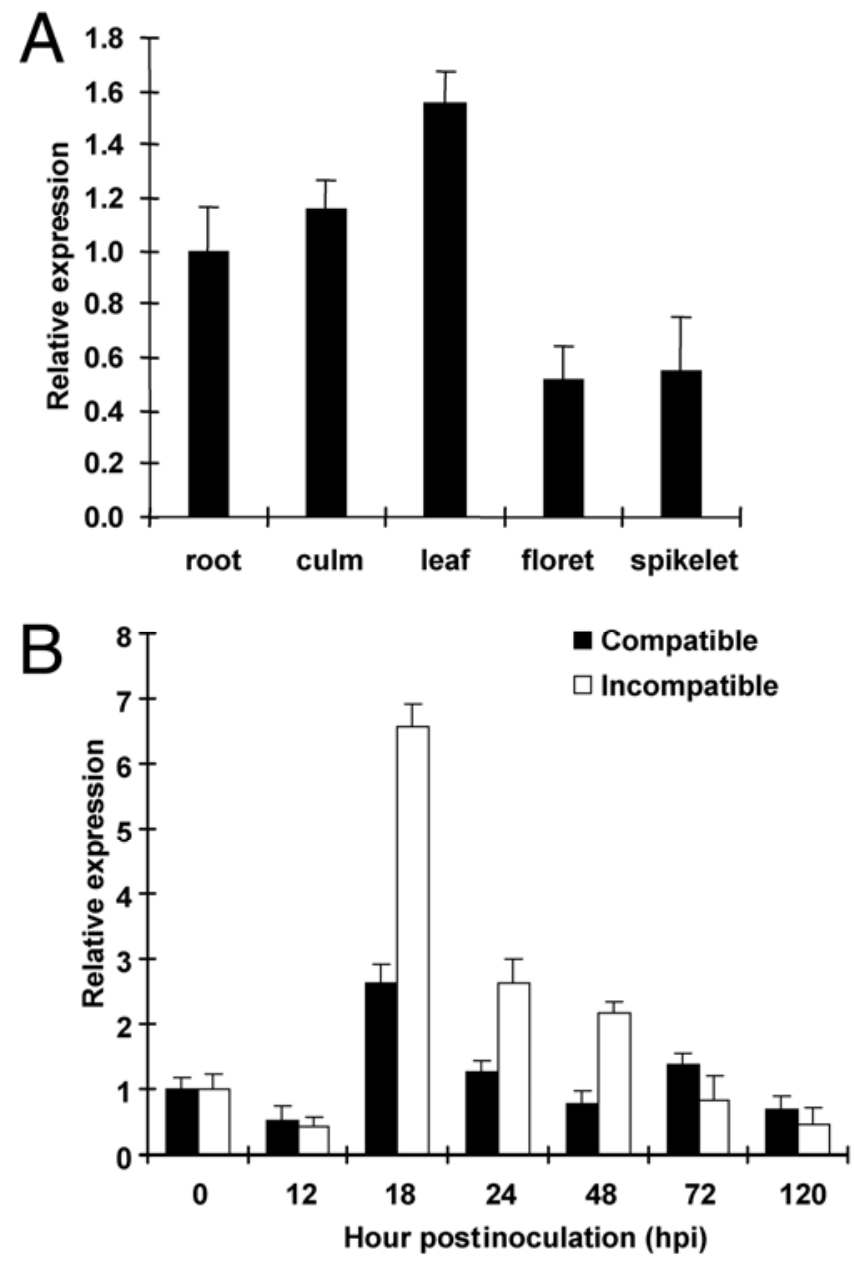

Fig. 2. Relative abundance of $T a D A D 2$ transcripts assayed by quantitative reverse-transcription polymerase chain reaction. A, Expression levels of TaDAD2 in leaf, culm, root, floret, and spikelet tissues. B, Expression levels of TaDAD2 in wheat leaves inoculated with CYR23 (incompatible reaction) and CYR31 (compatible reaction) sampled at $0,12,18,24,48,72$, and $120 \mathrm{~h}$ postinoculation. Relative gene quantification was calculated by the comparative threshold $(\Delta \Delta \mathrm{CT})$ method. Mean and standard deviation were calculated with data from three independent biological replicates.
TaDAD2as, as well as mock-inoculated plants (Fig. 5B). However, limited fungal sporulation around the necrotic spots was observed only on leaves infected with BSMV:TaDAD2as by 10 dpi (Fig. 5B). On average, approximately 17 uredia were formed on each $P$. striiformis f. tritici-inoculated leaf. In contrast, wheat leaves inoculated with CYR31 had normal disease development and produced numerous regular uredia (Fig. 5B), indicating that silencing of TaDAD2 has no effect on the compatible interaction. Race-specific resistance to the stripe rust fungus was not blocked or eliminated by BSMV:TaDAD2as infection or silencing of TaDAD2. Nevertheless, knocking down TaDAD2 expression reduced fungal-induced cell death and allowed limited fungal growth and uredium development equivalent to a reduced infection type of the wheat stripe rust fungus.

The relative expression levels of the TaPDS and TaDAD2 genes in the fourth leaves of infected plants were estimated by qRT-PCR. Inoculation with BSMV:TaPDSas resulted in a 64, 65 , and $72 \%$ reduction in the abundance of $T a P D S$ transcripts at 0,18 , and $48 \mathrm{hpi}$, respectively, compared with that of plants infected with BSMV: $\gamma$ (Fig. 5C). Similarly, the transcription level of $T a D A D 2$ was significantly reduced in leaves infected by BSMV:TaDAD2as (Fig. 5C). In comparison with BSMV: $\gamma-$ infected wheat leaves, the expression level of TaDAD2 in leaves infected with BSMV:TaDAD2as was reduced 71, 75, and $69 \%$ at 0,18 , and $48 \mathrm{hpi}$, respectively, with CYR23. Under similar conditions, inoculation with CYR31 caused 72, 70 and $67 \%$ reduction in TaDAD2 transcription in TaDAD2 knocked-down wheat plants at 0,18 , and $48 \mathrm{hpi}$, respectively (Fig. 5C). These results confirmed the reliability of the BSMVVIGS system for assessing potential effects of TaDAD2 silencing.

To determine whether the expression of defense-related genes was affected by TaDAD2 silencing, we assayed the expression levels of a few selected genes, including genes encoding pathogenesis-related (PR) proteins, involved in ROS generation and elimination, and related to secondary metabolism, in wheat leaves inoculated with the stripe rust fungus. The ex-

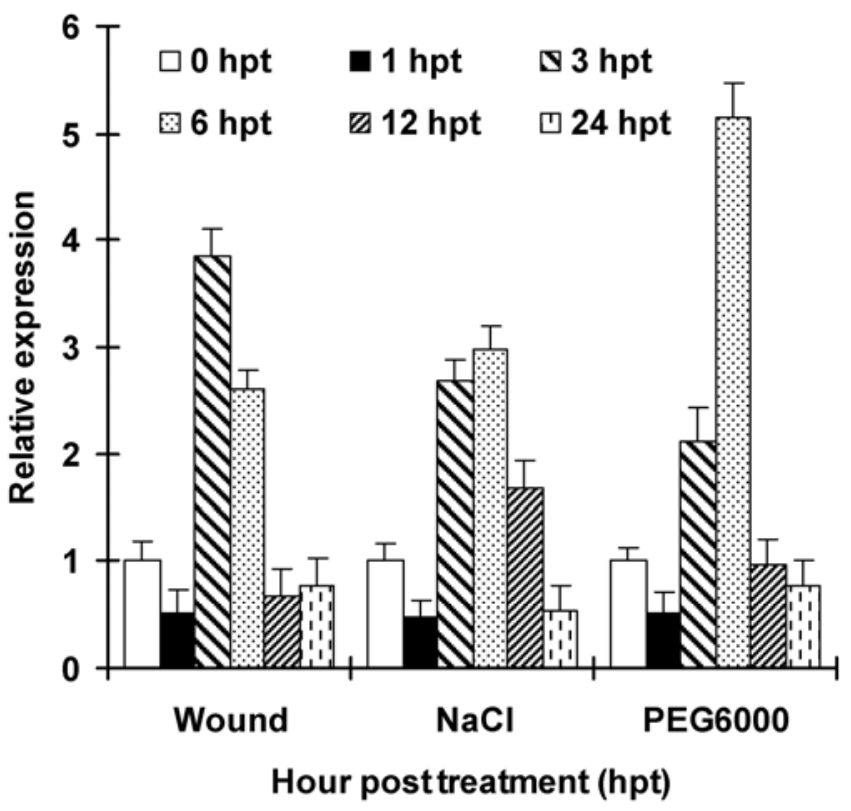

Fig. 3. Quantitative reverse-transcription polymerase chain reaction analyses of TaDAD2 expression in wheat treated with environmental stresses. Data were normalized to the expression level of wheat $18 \mathrm{~S}$ rRNA. Mean and standard deviation were calculated with data from three independent biological replicates. High salinity, $200 \mathrm{mM} \mathrm{NaCl}$; Drought, 20\% PEG6000; Wounding, wheat leaves cut with a pair of sterilized scissors. 
pression levels of the TaPR1, TaPR2, TaPR5, phenylalanine ammonia-lyase (TaPAL), and NADH oxidase (TaOXI) were reduced in TaDAD2 knocked-down leaves at 18 or 48 hpi with CYR23 (Fig. 6). In contrast, the expression of the catalase (TaCAT) and class III peroxidase (TaPOD) genes that are likely involved in ROS removal were induced in TaDAD2 knocked-down leaves infected with CYR23. The abundance of TaCAT transcripts increased almost 25-fold in comparison with the BSMV: $\gamma$-infected control wheat plants. Knocking down of TaDAD2 expression appeared to affect the expression of a number of plant defense-related genes.

\section{Histological observation of fungal growth and host response in TaDAD2 knocked-down plants.}

To determine cytological changes associated with enhanced susceptibility of TaDAD2 knocked-down plants to P. striiformis f. tritici, leaf segments inoculated with CYR23 or CYR31 were examined microscopically. Necrotic cells were not observed at 18 and 48 hpi on leaves inoculated with virulent race CYR31. Fungal development and host responses in CYR31-inoculated plants were similar to what have been described for compatible wheat- $P$. striiformis f. tritici interactions (C. F. Wang et al. 2007). In plants inoculated with CYR23, no significant differences in fungal development and hyphal growth were observed between mock-inoculated plants and TaDAD2 knocked-down plants at 18 hpi (Table 2). However, at 48 hpi, hyphal length in BSMV:TaDAD2as-infected wheat leaves was significantly $(P<$ $0.05)$ longer than those observed on mock-inoculated and BSMV: $\gamma$-infected plants (Table 2). These results indicated that the susceptibility of cv. Suwon11 to CYR23 was enhanced when TaDAD2 was silenced.

Hypersensitive cell death was further examined for discontinuity of cytoplasmic strands and from autofluorescence of dead cells. Similar to the previous report (C. F. Wang et al. 2007), necrotic cells were not observed by 18 hpi on leaves inoculated with avirulent race CYR23 (Fig. 7A). However, by 48 hpi, dead cells with autofluorescence were observed (Fig. $7 \mathrm{~B}-\mathrm{b}$ and c). Interestingly, the average necrotic area per infection site in the BSMV:TaDAD2as-infected plants was smaller than that of mock- and BSMV: $\gamma$-inoculated wheat plants, although occurrence of host cell necrosis was not significantly different (Fig.7B-b through d,), indicating that knocking down $T a D A D 2$ expression weakened hypersensitive cell death in the Suwon11-CYR23 interaction. In addition, fungal hyphae also were significantly longer compared with other treatments at 48 hpi. These results suggest that knocking down the transcription of $T a D A D 2$ in wheat increases its susceptibility to the wheat stripe rust fungus. Therefore, TaDAD2 may be involved in defense responses against the stripe rust fungus and suppression of plant cell death in wheat.

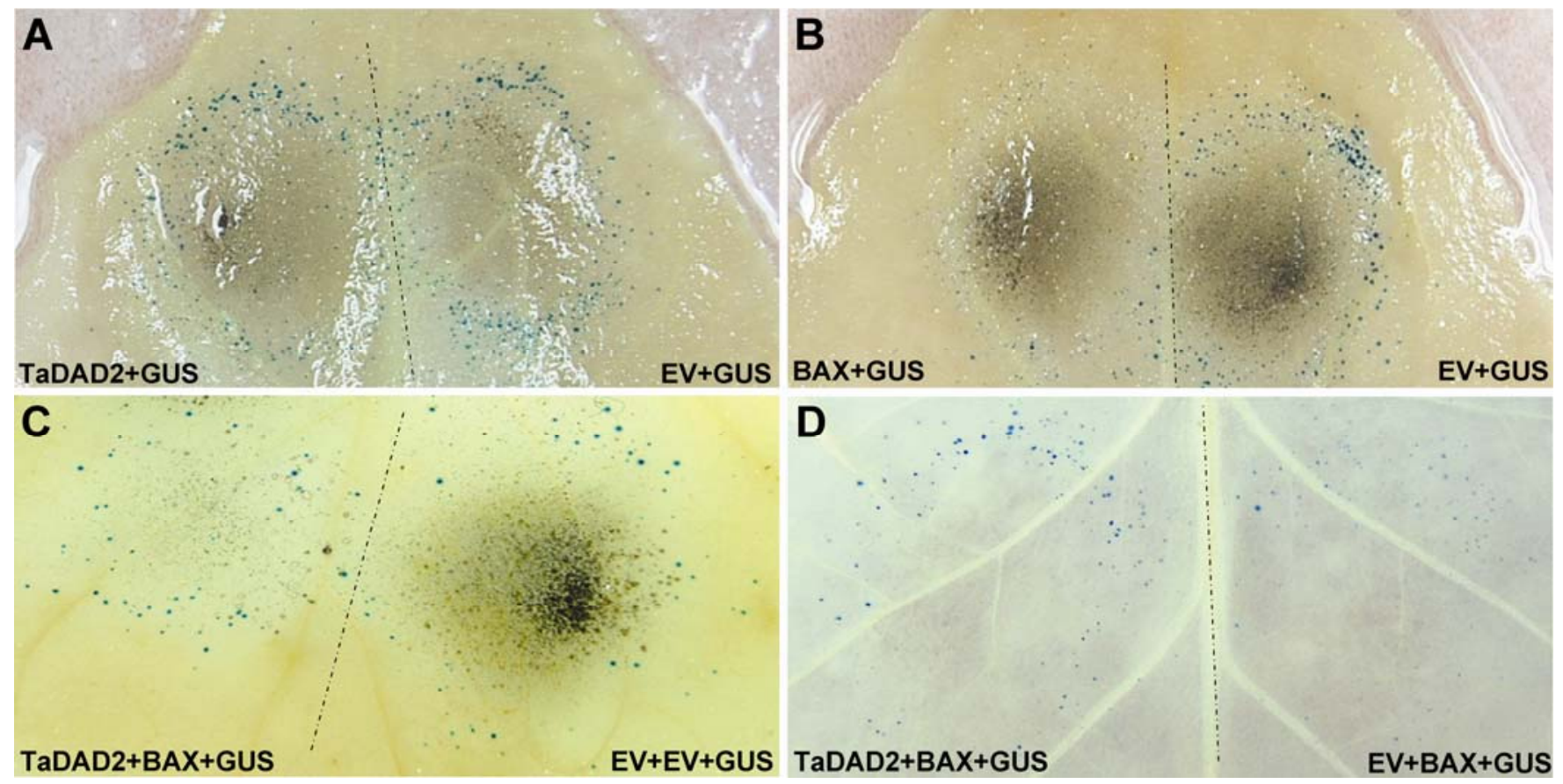

Fig. 4. A through D, Suppression of Bax-mediated programmed cell death by TaDAD2 in tobacco leaves bombarded with plasmid DNA samples as marked. EV, empty vector. Dotted line marks the position of a divider used to prevent the overlap of two bombardment areas.

Table 1. Suppression of Bax-mediated programmed cell death (PCD) by TaDAD2

\begin{tabular}{|c|c|c|c|c|c|}
\hline Treatment & Barrel 1 $^{\mathrm{w}}$ & Barrel 2 $^{\mathrm{w}}$ & Direct ratio $(\text { mean } \pm \mathrm{SE})^{\mathrm{x}}$ & Indirect ratio $^{y}$ & $P$ value $^{\mathrm{z}}$ \\
\hline $\mathrm{A}$ & TaDAD2+GUS & $\mathrm{EV}+\mathrm{GUS}$ & $0.94 \pm 0.01$ & N/A & N/A \\
\hline B & $\mathrm{Bax}+\mathrm{GUS}$ & $\mathrm{EV}+\mathrm{GUS}$ & $0.25 \pm 0.08$ & $\mathrm{C} / \mathrm{B}=2.4$ & $<0.05$ \\
\hline $\mathrm{C}$ & TaDAD2+Bax +GUS & $\mathrm{EV}+\mathrm{EV}+\mathrm{GUS}$ & $0.59 \pm 0.19$ & 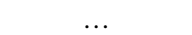 & . \\
\hline $\mathrm{D}$ & TaDAD2+Bax+GUS & $\mathrm{EV}+\mathrm{Bax}+\mathrm{GUS}$ & $2.13 \pm 0.50$ & N/A & $<0.05$ \\
\hline
\end{tabular}

${ }^{\mathrm{w}}$ Identical barrels, 1 and 2, were filled with the same amount of DNA samples as marked. EV, empty vector; $\beta$-glucuronidase (GUS), pUCGUS; Bax, pUCBax; TaDAD2, pUCTaDAD2.

${ }^{x}$ Direct ratios were the ratio of the logarithm of the number of blue spots produced by barrel 1 versus barrel 2. Mean and standard error (SE) were calculated from results from 16 pairs of bombardments.

${ }^{y}$ Comparison of the two averaged ratios from the experiments indicated by the capital letters. N/A = not applicable.

${ }^{\mathrm{z}} P$ values for the indirect comparisons were calculated from the log ratios using the Wilcoxon rank sum test. $P$ value for the direct comparison (treatment $\mathrm{D}$ ) was calculated from the $\log$ ratios using the Wilcoxon signed ranks test. A significant $P$ value indicates significant suppression of PCD. N/A $=$ not applicable. 


\section{DISCUSSION}

DAD proteins are well conserved among animals, plants, and fungi. In mammalian cells, DAD1 may act downstream from the bcl-2 protein to suppress cell death. In plants, there are only limited studies on the expression of $D A D$ genes in different developmental stages and in response to external stimuli. Like Arabidopsis and barley, wheat has two closely related $D A D$ genes. The wheat TaDAD2 gene was named after its closest ortholog, barley $H v D A D 2$. Similar to the rice and $A$. thaliana $D A D 1$ genes that can complement the tsBN7 cell line (Gallois et al. 1997; Orzáez and Granell 1997), TaDAD2 encodes a polypeptide with typical structural elements of DAD proteins. Although these two highly similar plant DAD proteins (Fig. 1B) likely have similar functions, the TaDAD2 gene and its orthologues have not been functionally characterized in plants.
Although barley, a diploid species, has only two $D A D$ genes, wheat is hexaploid and may possess more $D A D$ genes. Unfortunately, the wheat genome has not been sequenced. We isolated two DAD genes, TaDAD1 and TaDAD2, in the cDNA library enriched for wheat genes induced by the stripe rust fungus. No additional $D A D$ genes were identified by Blast searches in the GenBank and wheat-specific databases. One possible explanation is that other wheat $D A D$ genes are not expressed or expressed at a very low level in the tissues used for cDNA library construction.

When it was expressed in $N$. benthamiana, the TaDAD2 could reduce the frequency of PCD induced by a mammalian Bax gene, indicating that TaDAD2 may function as a negative regulator of PCD in wheat. Because hypersensitive response of resistant plants to avirulent pathogens is a form of cell death,

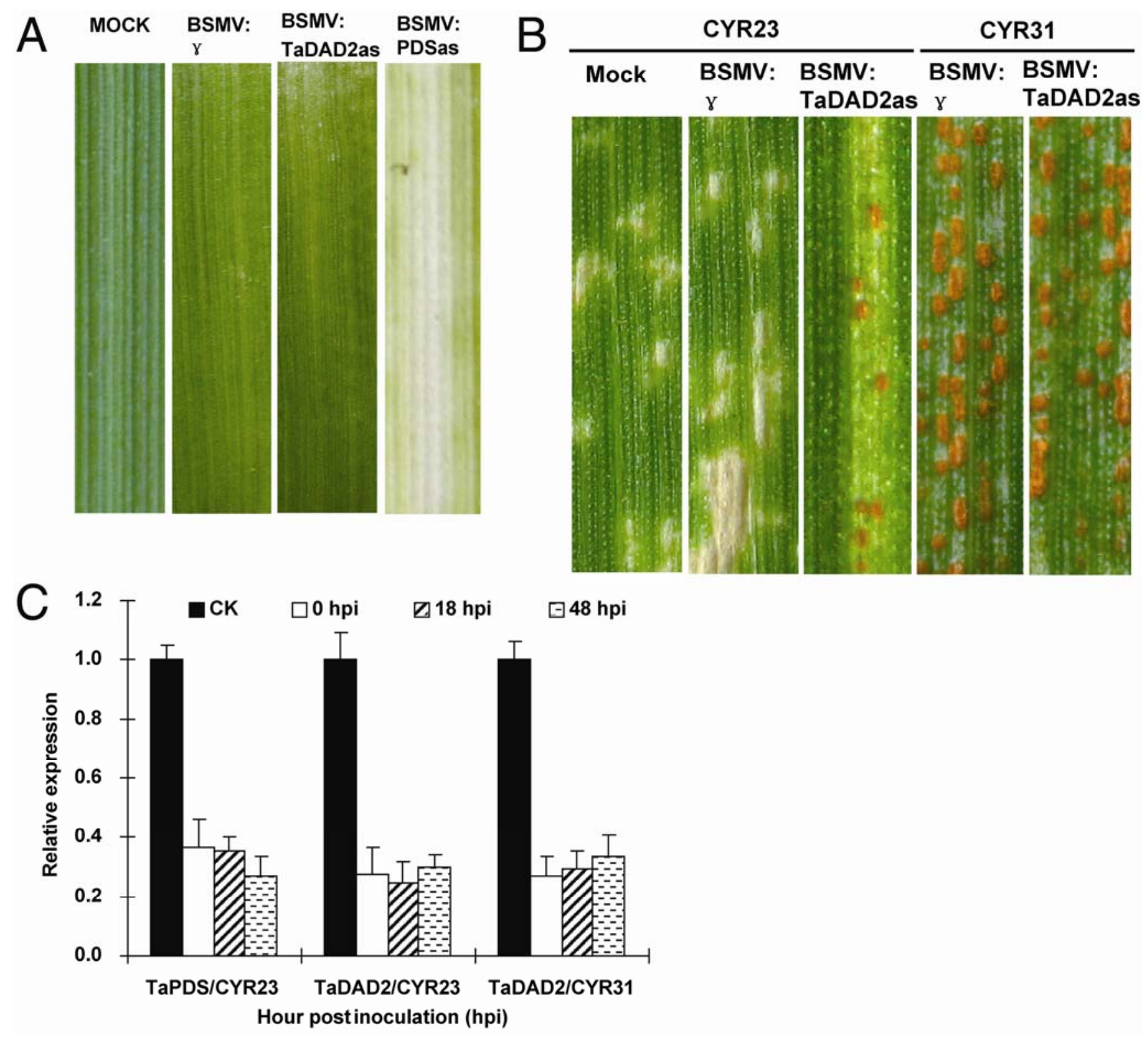

Fig. 5. Functional characterization of the TaDAD2 gene by the Barley stripe mosaic virus (BSMV)-based virus-induced gene silencing method. A, Mild chlorotic mosaic symptoms were observed on the leaves inoculated with BSMV: $\gamma$ or BSMV:TaDAD2as at 9 days postinoculation (dpi). Photobleaching was evident on leaves infected with BSMV:TaPDSas at 15 dpi but not on mock-inoculated leaves. B, Leaves inoculated with BSMV: $\gamma$ or BSMV:TaDAD2as and urediospores of avirulent race CYR23 or virulent race CYR31. Mock: wheat leaves treated with Fes buffer. Typical leaves were photographed 15 dpi. C, Relative transcript levels of TaDAD2 and TaPDS assayed by quantitative reverse-transcription polymerase chain reaction. RNA samples were isolated from the fourth leaves of the wheat seedlings infected by BSMV:TaDAD2as and BSMV:TaPDSas at 0,18 , and $48 \mathrm{~h}$ postinoculation (hpi) after inoculation with CYR23 or CYR31. CK: wheat leaves infected with BSMV: $\gamma$ were sampled immediately (0 hpi) after inoculation with CYR23 or CYR31. Data were normalized to the 18S rRNA expression level. Error bars represent the variations among three independent replicates. 
$T a D A D 2$ may function as one of the regulatory components of this important reaction to restrict pathogen growth.

Although TaDAD2 is expressed in all wheat tissues tested, the expression of TaDAD2 was reduced as early as $12 \mathrm{hpi}$ in both compatible and incompatible wheat- $P$. striiformis $\mathrm{f}$. tritici interactions, suggesting that TaDAD2 expression displays a nonspecific response at early stages of the wheat $-P$. striiformis f. tritici interaction. As a biotrophic fungal pathogen, the wheat stripe rust fungus must suppress plant defense responses (Skalamera and Heath 1998) and establish an intimate relationship with the host involving the development of haustoria. $T a D A D 2$ expression also was reduced in response to different stresses as early as $1 \mathrm{hpt}$. These results indicate that TaDAD2 may have the basic function of aiding the survival of wheat cells against biotic or abiotic stresses during the initial reaction. Nonspecific stress reactions and plant defense responses share a number of physiological events such as the accumulation of ROS species. Plant survival factors may sense stress signals and contribute to the regulation of defense reactions, which may lead to cell death when reaching a certain threshold (Jones and Dangl 2006).
Induced expression of $D A D 1$ orthologues in Araneus ventricosus, Mayetiola destructor, and Argopecten irradians have been shown to be related to defense against unwanted cell death upon exposure to external stimuli (Lee et al. 2003; Mittapalli and Shukle 2008; Zhu et al. 2008). Upregulation of DAD1 genes was also observed during development in C. elegans (Sugimoto et al. 1995) and Bombyx mori (Tsusuki et al. 2001). In contrast, downregulation of a $D A D 1$ gene was observed in plant flower petals during the senescence phase (Orzáez and Granell 1997). These studies indicate the involvement of $D A D 1$ genes in specific development processes and responses to external stimuli. In this study, we found that transcripts of TaDAD2 could be readily detected in all the wheat tissues examined, which is similar to the expression profiles of AtDAD1 in Arabidopsis thaliana (Gallois et al. 1997). The TaDAD2 gene may be involved in certain plant growth and developmental processes in wheat.

In animal cells, $D A D 1$ is constitutively expressed in all cells except those that are undergoing cell death (Nakashima et al. 1993). Because only a small fraction of cells are likely to be undergoing cell death in complex organs or tissues, we expect
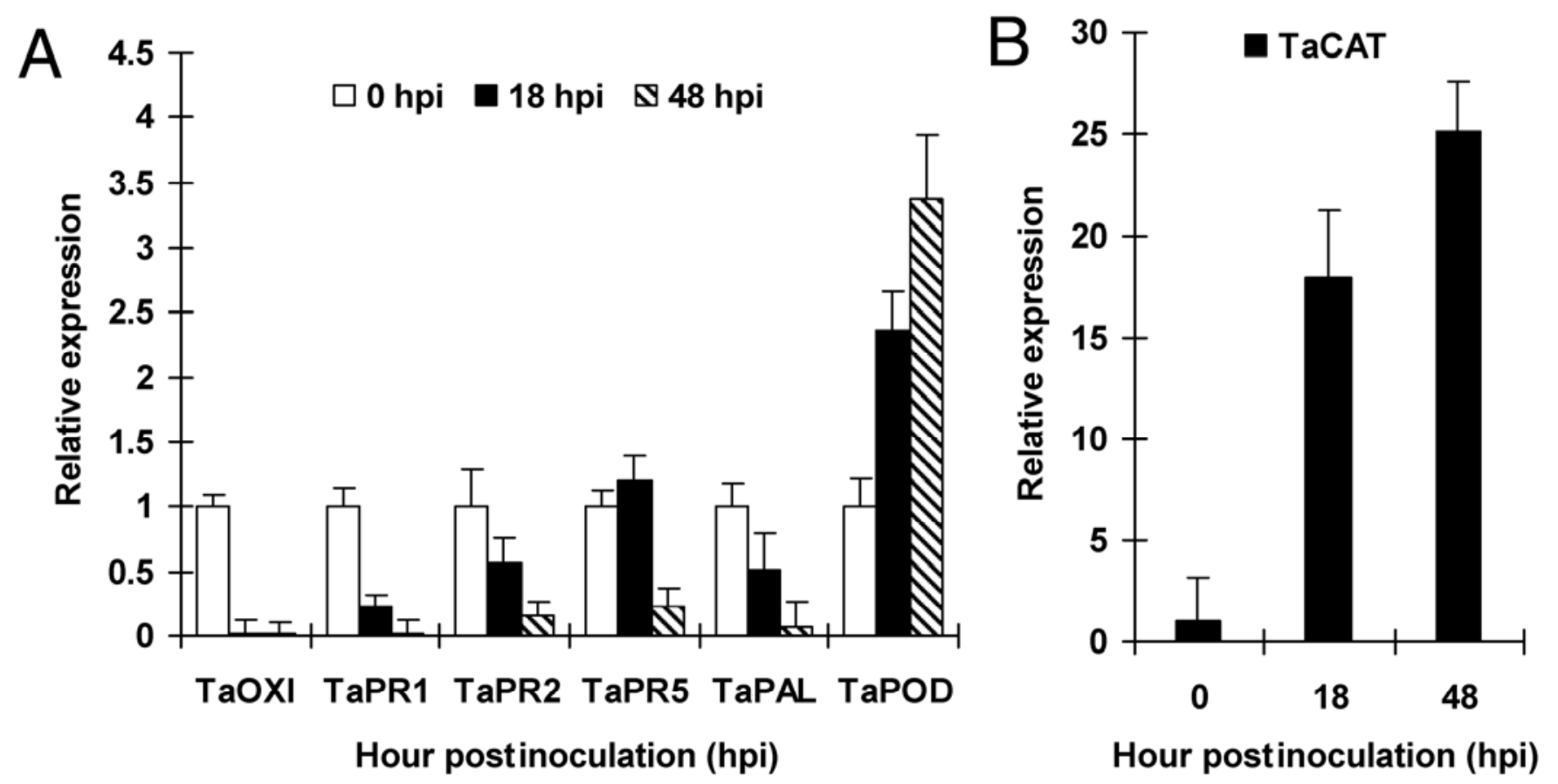

Fig. 6. Quantitative reverse-transcription polymerase chain reaction assays for the expression of resistance-related genes in TaDAD 2 knocked-down wheat seedlings in response to Puccinia striiformis f. tritici infection. Accession numbers are A, TaPAL phenylalanine ammonia-lyase (TC294834), TaPOD class III peroxidase (TC303653), TaOXI NADH oxidase (TC340651), TaPR1 (AAK60565), TaPR2 (DQ090946), and TaPR5 (FG618781); B, TaCAT Catalase (X94352). Sequences of genes with their accession numbers starting with letters TC were downloaded from online wheat-specific databases. Mock- and BSMV-treated leaves were sampled at 0,18 , and 48 hpi after $P$. striiformis f. tritici infection. Data were normalized to the $18 \mathrm{~S}$ rRNA expression level. Error bars represent the variations among three independent replicates.

Table 2. Histological observation during the incompatible interaction between wheat and stripe rust fungus when the transcription of $T a D A D 2$ was repressed

\begin{tabular}{|c|c|c|c|c|c|c|}
\hline \multirow[b]{2}{*}{ Treatment $^{\mathrm{z}}$} & \multicolumn{2}{|c|}{ Necrotic cell $(\%)^{w}$} & \multicolumn{2}{|c|}{ Necrotic area per infection site $\left(\mu \mathrm{m}^{2}\right)^{x}$} & \multicolumn{2}{|c|}{ Hyphal length $(\mu \mathrm{m})^{y}$} \\
\hline & 18 hpi & 48 hpi & 18 hpi & 48 hpi & 18 hpi & 48 hpi \\
\hline Control & - & 94 & - & $104.2 \mathrm{a}$ & $5.24 \mathrm{a}$ & $5.43 \mathrm{~b}$ \\
\hline BSMV: $\gamma$ & - & 96 & - & $116.9 \mathrm{a}$ & $5.02 \mathrm{a}$ & $5.32 \mathrm{~b}$ \\
\hline BSMV:TaDAD2as & - & 90 & - & $74.96 \mathrm{~b}$ & $5.28 \mathrm{a}$ & $6.30 \mathrm{a}$ \\
\hline
\end{tabular}

v Abbreviations: hpi, hours postinoculation; -, no necrotic cells observed.

${ }^{\mathrm{w}}$ Percentage of dead mesophyll cells.

${ }^{x}$ Area of dead mesophyll cells around an infection site (length $\times$ width of individual dead spots).

${ }^{\mathrm{y}}$ Distance from the base of substomatal vesicles to hyphal tips. Values followed by the same letter are not significantly different at $P=0.05$ according to the Tukey's test.

${ }^{\mathrm{z}}$ Control, untreated leaves infected with CYR23; BSMV: $\gamma$ and BSMV:TaDAD2as, leaves inoculated with BSMV: $\gamma$ and BSMV:TaDAD2as followed by infection with CYR23. 
that variation in TaDAD2 expression after $P$. striiformis $\mathrm{f}$. tritici infection would be minor. However, the abundance of TaDAD2 mRNA in wheat leaves varied substantially at different time points after $P$. striiformis f. tritici infection. The expression profile of TaDAD2 differed from what we expected based on the expression of its orthologues in animal cells, and leads us to question whether $D A D$ plays a similar biological role in plants as it does in animals. Of course, it is also possible that different members of the $D A D$ gene family show different expression patterns and have different biological functions.

Necrotic cell area per infection site was significantly reduced and hyphal length was increased when TaDAD2 was knocked down by BSMV-VIGS, indicating that the susceptibility to $P$. striiformis f. tritici was enhanced when TaDAD2 was silenced in wheat cv. Suwon11. Few small uredia were observed on leaves infected with CYR23 in TaDAD2 knocked-down plants. In addition, the expression levels of a few defense-related genes also were reduced in BSMV:TaDAD2as-infected wheat leaves challenged by CYR23 (Fig. 6), suggesting that the resistance to CYR23 was weakened. Therefore, TaDAD2 is important for basal level resistance to the stripe rust fungus. The degree of induced TaDAD2 expression was higher in the incompatible interaction than the compatible interaction, also indicating a role of TaDAD2 in defense against $P$. striiformis f. tritici infection. When the expression of TaDAD2 was knocked down by
VIGS, cell death was reduced instead of enhanced at $48 \mathrm{hpi}$. We speculate that TaDAD2 may have the opposite or no effect on cell death triggered by stripe rust fungus at late infection stages. Weakened resistance may result from compromised cell death at late stages of the wheat- $P$. striiformis f. tritici interaction.

Transgenic NahG Arabidopsis plants expressing a bacterial SA hydroxylase that metabolizes SA to catechol are defective in SAR and induced $P R$ gene expression, and compromised in local $R$-gene-dependent resistance responses (Delaney et al. 1994; Gaffney et al. 1993). Therefore, we assessed the TaPAL and $P R$ gene expression levels by qRT-PCR analysis. When TaDAD2 knocked-down plants were inoculated with avirulent race CYR23, the transcripts of $P R 1, P R 2, P R 5$, and TaPAL were significantly reduced. Phenylalanine ammonia-lyase $(P A L)$ is a key enzyme in SA synthesis, and the $P R$ genes are generally regarded as markers for hypersensitive or resistance response (Van Loon 1997; Van Loon and Van Strien 1999). Therefore, reduced expression of TaPAL and these $P R$ genes may be responsible for compromised resistance to the avirulent pathotype.

ROS is one of the earliest messenger molecules that function at the early stage in signal regulation, stress adaptation, and PCD (Yoshinaga et al. 2005 a and b). In wheat, silencing of $T a D A D 2$ resulted in increased expressions of putative ROSscavenging genes and repression of ROS-generating genes (Fig. 6). It is likely that ROS accumulation was reduced in
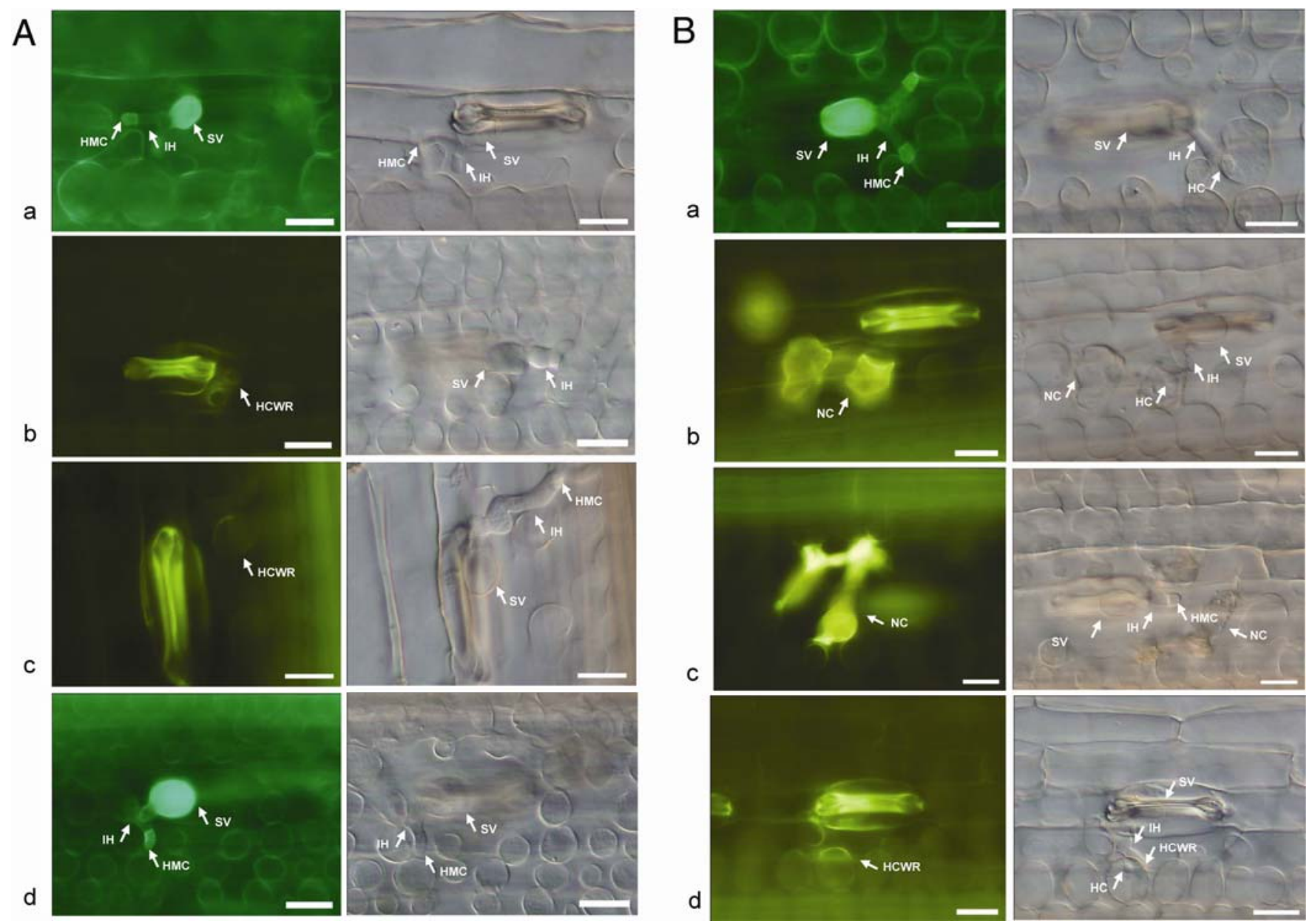

Fig. 7. Histological observation of fungal growth and host cell death in wheat leaves treated with recombinant Barley stripe mosaic virus (BSMV) viruses and infected with avirulent race CYR23 or virulent race CYR31. Typical leaves were examined at A, 18 or B $48 \mathrm{~h}$ postinoculation. The same infection site was observed by epifluorescence (left panels, EF) or differential interference contrast (DIC) microscopy. Treatments were a, BSMV:TaDAD2as infected leaves inoculated with CYR31; b, mock-inoculated leaves challenged by CYR23; c, BSMV: $\gamma$ infected leaves inoculated with CYR23; d, BSMV:TaDAD2as infected leaves inoculated with CYR23. Bars $=25 \mu \mathrm{m}$. SV, substomatal vesicle; HMC, haustorial mother cell; IH, infection hypha; H, haustorium; NC, necrotic cell, HR, hypersensitive response; HCWR, host cell wall response. 
TaDAD2 knocked-down wheat leaves, which may compromise HR to CYR23 infection. Oxidative stress has been linked to the Bax-induced cell death. Expression of mammalian Bax genes disrupts mitochondrial membrane potential and results in ROS accumulation and changes in mitochondrial morphology in plant and yeast cells (Baek et al. 2004; Madeo et al. 1999; Yoshinaga et al. 2005a and b). Although DAD as a cell death suppressor has a similar function with BI-1 in animals, further studies are needed to determine the molecular mechanisms of relationship between TaDAD2 and ROS production at early stages in the wheat $-P$. striiformis f. tritici incompatible interaction.

\section{MATERIALS AND METHODS}

\section{Plant materials, inoculation, and treatments.}

Seedlings of wheat cv. Suwon 11 were maintained and inoculated with $P$. striiformis f. tritici pathotype CYR23 (avirulent) or CYR31 (virulent) following the procedures and conditions as described (Kang et al. 1984; Liu et al. 2006; Stakman 1915). Suwon 11 carrying the $\mathrm{YrSu}$ resistance gene shows a typical HR to CYR23 but is highly susceptible to CYR31. Wheat plants inoculated with sterile distilled water were used as mock-inoculation controls. Leaves were harvested at 0,12 , $18,24,48,72$, and $120 \mathrm{hpi}$ for RNA isolation. These time points were selected based on microscopic studies of the interactions between Suwon 11 and CYR23 or CYR31 (C. F. Wang et al. 2007). Disease symptoms were scored 15 dpi.

For high-salinity and draught-stress treatments, roots of wheat seedlings were soaked in $200 \mathrm{mM} \mathrm{NaCl}$ or $20 \%$ PEG6000. Wounding treatment was applied by cutting wheat leaves with a pair of sterilized scissors. Wheat seedlings treated with various stress elicitors were sampled at $0,1,3,6,12$, and $24 \mathrm{hpt}$. All samples were rapidly frozen in liquid nitrogen and stored at $-80^{\circ} \mathrm{C}$. Three independent biological replications were performed for each time point.

\section{DNA and RNA extraction and qRT-PCR.}

Genomic DNA samples were prepared from etiolated seedlings as described (X. J. Wang et al. 2007). RNA was isolated with the Trizol Reagent (Invitrogen, Carlsbad, CA, U.S.A.) following the instructions provided by the supplier. Firststrand cDNA was synthesized with the GoScript ReverseTranscription System (Promega Corp., Madison, WI, U.S.A.). Primer design and qRT-PCR reactions were conducted as described previously (Wang et al. 2009). Quantification of gene expression was performed using a 7500 Real-Time PCR System (Applied Biosystems, Foster City, CA, U.S.A.). To avoid variations caused by experimental conditions, the expression level of TaDAD2 in the mock-inoculated control was subtracted from that in wheat leaves inoculated with $P$. striiformis f. tritici or treated with abiotic stresses for analyzing changes in TaDAD2 transcription in the same time-course study. The abundance of wheat 18S rRNA (GenBank accession number AY049040) was assayed as the internal control for normalization. For assaying the expression level of $18 \mathrm{~S}$ rRNA in response to $P$. striiformis f. tritici infection or abiotic stresses, the wheat elongation factor TaEF-1a gene (GenBank accession number Q03033) was used as the internal reference for qRTPCR analysis. No significant changes were detected in the abundance of $18 \mathrm{~S}$ rRNA at different time points after $P$. striiformis f. tritici infection or stress treatment (Supplementary Fig. S1). Dissociation curves were generated for each reaction to ensure specific amplification. Threshold values (CT) generated from the ABI PRISM 7500 Software Tool (Applied Biosystems) were used to quantify relative gene expression using the comparative $2^{-\Delta \Delta C T}$ method (Livak and Schmittgen 2001).
Isolation of cDNA and genomic sequences.

Primers TaDAD2-S and TaDAD2-AS were designed according to the sequence of cDNA clone WRIC_1264 (accession number GR303076) from a cDNA library during wheat- $P$. striiformis f. tritici interactions (Ma et al. 2009). They were used to amplify a TaDAD2 fragment from the first cDNA synthesized with RNA isolated from Suwon 11 leaves harvested at 24 hpi with CYR23. The full-length cDNA sequences of TaDAD2 were generated by sequencing 5' and 3' RACE products amplified with the SMART RACE cDNA amplification kit (Clontech Laboratories, Inc., Palo Alto, CA, U.S.A.). The genomic sequence of TaDAD2 was obtained by sequencing PCR products amplified with primers TaDAD2_genome-S and TaDAD2_ genome-AS. The Universal genome walker kit (BD Biosciences Clontech, Palo Alto, CA, U.S.A.) was used to isolate flanking genomic sequences of TaDAD2 following the manufacturer's instructions.

\section{Sequence analysis, alignment, and domain prediction.}

The amino acid sequence of TaDAD2 was analyzed with InterProScan and PROSITE Scan for conserved domains or motifs. TargetIP and TMPRED were used to predict signal peptide and transmembrane domains. Multiple sequence alignments were created with ClustalW (Thompson et al. 1994). Phylogenetic analysis of TaDAD2 and DAD members was carried out at the Mega website. Phylogenetic trees were constructed with neighbor joining, minimal evolution, or parsimony programs (Nei and Kumar 2000). The bootstrap values were estimated based on 500 replications. The HsDAD (Homo sapiens) was employed as the outgroup control for the construction of phylogenetic trees. Gene structure was predicted by FGENESH.

\section{Detection of $T a D A D 2$ transcripts in wheat organs.}

Wheat leaf, root, culm, floret, and spikelet samples were collected from wheat plants at the flowering stage. The relative transcript levels of TaDAD2 in RNA isolated from these four organs were evaluated by qRT-PCR with gene-specific primers.

\section{Plasmids construction.}

Tobacco ( $N$. benthamiana) transient expression plasmids pUCTaDAD2 (TaDAD2 driven by the Cauliflower mosaic virus [CaMV] 35S promoter), pUCBax (Bax gene driven by the CaMV 35S promoter), and pUCGUS (GUSPlus gene driven by the CaMV $35 \mathrm{~S}$ promoter) were constructed as described by Dou and associates (2008). Plasmid pUCATaDAD2 was obtained by replacing the Bax gene on pUCBax with the TaDAD2-ORF fragment.

Plasmids used for gene silencing are based on the constructs described by Holzberg and associates (2002). The two RNA-derivative clones (BSMV:TaPDSas and BSMV:TaDAD2as) were created using BSMV:GFP (green fluorescent protein) cDNA as the starting material. A cDNA fragment $(120 \mathrm{bp})$ of the wheat phytoene desaturase gene TaPDS was obtained by RT-PCR. This fragment, in an antisense orientation, was used to replace the GFP coding sequence in BSMV:GFP, resulting in BSMV: TaPDSas. With a similar approach, BSMV:TaDAD2as was prepared using a 161-bp TaDAD2 cDNA fragment derived from its coding sequence and $3^{\prime}$ untranslated region.

\section{Particle bombardment assays.}

Leaves from 4- to 6-week-old $N$. benthamiana plants were bombarded using the Bio-Rad He/1000 particle delivery system with a double-barreled extension attached as described (Dou et al. 2008). Plasmid DNA was prepared and resuspended to 5 to $6 \mu \mathrm{g} / \mu \mathrm{l}$ in sterile deionized water. For bombardment, $9 \mathrm{mg}$ of M-10 tungsten particles (Bio-Rad, Hercules, 
CA, U.S.A) were combined with $50 \mu \mathrm{g}$ of pUCGUS DNA and $60 \mu \mathrm{g}$ of empty vector (pUC19), or $10 \mu \mathrm{g}$ of pUCBax and 50 $\mu \mathrm{g}$ of pUC19, or $50 \mu \mathrm{g}$ of pUCTaDAD2 and $10 \mu \mathrm{g}$ of pUCBax. After bombardment, leaves were incubated at $28^{\circ} \mathrm{C}$ for 3 days in darkness and then stained for $16 \mathrm{~h}$ at $28^{\circ} \mathrm{C}$ using 5-bromo-4-chloro-3-indolyl-D-glucuronic acid at $0.8 \mathrm{mg} / \mathrm{ml}$, $80 \mathrm{mM} \mathrm{Na}$ phosphate (pH 7.0), $0.4 \mathrm{mM} \mathrm{K}_{3} \mathrm{Fe}(\mathrm{CN})_{6}, 0.4 \mathrm{mM}$ $\mathrm{K}_{4} \mathrm{Fe}(\mathrm{CN})_{6}, 8 \mathrm{mM} \mathrm{Na} \mathrm{NDDTA}_{2}, 20 \%$ methanol, and $0.06 \%$ (vol/vol) Triton X-100. After destaining in $100 \%$ methanol for $12 \mathrm{~h}$, blue spots were counted under a dissecting microscope.

To quantify the suppression of Bax-mediated cell death, plasmid pUCTaDAD2 $(1.7 \mu \mathrm{g} / \mathrm{shot})$ was mixed with pUCBax $(0.33$ $\mu \mathrm{g} / \mathrm{shot})$ and pUCGUS $(1.7 \mu \mathrm{g} / \mathrm{shot})$ and bombarded into tobacco leaves. The control shot in the second barrel was the mixture of empty vector pUC19 $(2.0 \mu \mathrm{g} / \mathrm{shot})$ and GUS DNA (1.7 $\mu \mathrm{g} / \mathrm{shot})$. For each pair of shots, the ratio of the logarithm of the blue spots formed on leaves bombarded with Bax to that with the empty vector control or with Bax and TaDAD2 to that with the empty vector control was calculated. The log ratios for these shots were then compared with the log ratios obtained when $T a D A D 2$ DNA was replaced by the empty vector DNA. Each assay consisted of eight pairs of shots and was conducted at least twice. Results were evaluated using the Wilcoxon rank sum test (SAS software; SAS Institute Inc., Cary, NC, U.S.A.). For direct assays of the suppression of Bax-induced cell death by TaDAD2, tobacco leaves were bombarded with a mixture of pUCTaDAD2 $(1.7 \mu \mathrm{g})$, pUCBax $(0.33 \mu \mathrm{g})$, and pUCGUS $(1.7 \mu \mathrm{g})$ in the first barrel and a mixture of empty vector pUC19 $(1.7 \mu \mathrm{g})$, pUCGUS $(1.7 \mu \mathrm{g})$, and pUCBax $(0.33 \mu \mathrm{g})$ in the second barrel. The ratio of the logarithm of the blue spots formed on leaves bombarded with Bax and TaDAD2 to that with the empty vector and Bax was calculated. In total, 16 pairs of shots were performed for each comparison, and the results were calculated from the log ratios using the Wilcoxon signed ranks test (SAS software; SAS Institute Inc.).

\section{BSMV-mediated TaDAD2 gene silencing.}

Capped in vitro transcripts were prepared from linearized plasmids that contain the tripartite BSMV genome (Petty et al. 1990) using the mMessage mMachine T7 in vitro transcription kit (Ambion, Austin, TX, U.S.A.) following the manufacturer's instructions. Wheat seedlings of the two-leaf stage were infected with BSMV as described (Scofield et al. 2005), maintained in a growth chamber at $23 \pm 2{ }^{\circ} \mathrm{C}$, and examined for symptoms at regular intervals. Once photobleaching was observed, three independent sets of inoculations were performed, with a total of 72 seedlings inoculated for each of the three BSMV viruses (BSMV: $\gamma$, BSMV:TaPDSas, and BSMV:TaDAD2as). For the control, 24 seedlings were mock inoculated with $1 \times$ Fes buffer (Pogue et al. 1998). The third leaf of a three-leaf wheat seedling was inoculated with BSMV transcripts by gently rubbing the surface with a gloved finger (Hein et al. 2005; Holzberg et al. 2002; Scofield et al. 2005). At 9 dpi, the fourth leaf was infected with urediniospores of CYR23 or CYR31. Infection types of stripe rust were examined $15 \mathrm{dpi}$. The number of uredia formed on each leaf section was counted at $240 \mathrm{hpi}$. The fourth leaves also were sampled at 0,18 , and 48 hpi for histological observation and RNA isolation.

Primers used for assaying the expression levels of the TaPRl, TaPR2, TaPR5, TaCAT, TaPOD, TaPAL, and TaOXI genes in $T a D A D 2$ knocked-down plants were listed in Supplementary Table 1.

\section{Histological observation \\ of fungal growth and host response.}

Wheat leaves infected with BSMV were sampled at 0,18 , and 48 hpi with $P$. striiformis f. tritici and stained as described
(C. F. Wang et al. 2007). Cleared leaf segments were examined with an Olympus BX-51 microscope (Olympus Corp., Tokyo) for infection sites and lengths of infection hyphae. Autofluorescence of attacked mesophyll cells was observed as a necrotic death area by epifluorescence microscopy (excitation filter, $485 \mathrm{~nm}$; dichromic mirror, $510 \mathrm{~nm}$; and barrier filter, $520 \mathrm{~nm}$ ). At least 50 infection sites were examined on each of five randomly selected leaf segments per treatment. Only infection sites where appressoria had formed over stomata were considered to have successful penetration and were examined for the formation of substomatal vesicles, infection hyphae, and haustorium mother cells. Following the classification of Parlevliet (1986), all nonpenetrating appressoria and aborted substomatal vesicles were considered to be aborted penetration attempts. The percentage of infection sites displaying host cell necrosis also was recorded. The necrotic leaf area was measured with a calibrated eyepiece micrometer and corresponding areas (square micrometers) calculated according to the formula $\pi \times$ length $\times$ width/4. Standard deviations and Tukey's test for statistical analysis were performed with the SAS software.

\section{ACKNOWLEDGMENTS}

We thank S. R Scofield for providing BSMV vectors and D. Dou for providing expression vectors. Financial support for this work was obtained from the National Natural Science Foundation of China (no. 30930064), the National Major Project of Breeding for New Transgenic Organisms (2008ZX08002-001 and 2009ZX08009-051B), and the 111 Project from the Ministry of Education of China (B07049).

\section{LITERATURE CITED}

Baek D., Nam, J., Koo, Y. D., Kim, D. H., Lee, J., Jeong, J. C., Kwak, S. S., Chung, W. S., Lim, C. O., Bahk, J. D., Hong, J. C., Lee, S. Y., Kawai-Yamada, M., Uchimiya, H., and Yun, D. J. 2004. Bax-induced cell death of Arabidopsis is meditated through reactive oxygen-dependent and independent processes. Plant Mol. Biol. 56:15-27.

Bolwell, G. P. 1999. Role of active oxygen species and NO in plant defense responses. Curr. Opin. Plant Biol. 2:287-294.

Brewster, J. L., Martin, S. L., Toms, J., Goss, D., Wang, K., Zachrone, K., Davis, A., Carlson, G., Hood, L., and Coffin, J. D. 2000. Deletion of Dad1 in mice induces an apoptosis-associated embryonic death. Genesis 26:271-278.

Chandok, M. R., Ytterberg, A. J., van Wijk, K. J., and Klessig, D. F. 2003. The pathogen-inducible nitric oxide synthase (iNOS) in plants is a variant of the P protein of the glycine decarboxilase complex. Cell 113:469482.

Delaney, T. P., Uknes, S., Vernooij, B., Friedrich, L., Weymann, K., Negrotto, D., Gaffney, T., Gutrella, M., Kessmann, H., Ward, E., and Ryals, J. 1994. A central role of salicylic acid in plant disease resistance. Science 266:1247-1250.

Delledonne, M. 2005. NO news is good news for plants. Curr. Opin. Plant Biol. 8:390-396.

Dou, D. L., Kale, S. D., Wang, X. L., Chen, Y. B., Wang, Q. Q., Wang, X., Jiang, R. H. Y., Arredondo, F. D., Anderson, R. G., Thakur, P. B. McDowell, J. M., Wang, Y. C., and Tyler, B. M. 2008. Conserved Cterminal motifs required for avirulence and suppression of cell death by Phytophthora sojae effector Avr1b. Plant Cell 20:1118-1133.

Gaffney, T., Friedrich, L., Vernooij, B., Negrotto, D., Nye, G., Uknes, S., Ward, E., Kessmann, H., and Ryals, J. 1993. Requirement of salicylic acid for the induction of systemic acquired resistance. Science 261:754756.

Gallois, P., Makishima, T., Hechtt, V., Despres, B., Laudie, M., Nishimoto, T., and Cooke, R. 1997. An Arabidopsis thaliana cDNA complementing a hamster apoptosis suppressor mutant. Plant J. 11:1325-1331.

Gechev, T. S., Van Breusegem, F., Stone, J. M., Denev, I., and Laloi, C. 2006. Reactive oxygen species as signals that modulate plant stress responses and programmed cell death. Bioessays 28:1091-1101.

Geske, F. J., and Gerschenson, L. E. 2001. The biology of apoptosis. Hum. Pathol. 32:1029-1038.

Heath, M. C. 2000. Hypersensitive response related death. Plant Mol. Biol. 44:321-334.

Hein, I, Barciszewska-Pacak, M., Hrubikova, K., Williamson, S., Dinesen, 
M., Soenderby, I. E., Sundar, S., Jarmolowski, A., Shirasu, K., and Lacomme, C. 2005. Virus-induced gene silencing based functional characterization of genes associated with powdery mildew resistance in barley. Plant Physiol. 38:2155-2164.

Higuchi, Y. 2003. Chromosomal DNA fragmentation in apoptosis and necrosis induced by oxidative stress. Biochem. Pharmacol. 66:15271535 .

Holzberg, S, Brosio, P., Gross, C., and Pogue, G. P. 2002. Barley stripe mosaic virus-induced gene silencing in a monocot plant. Plant $\mathrm{J}$. 30:315-327.

Jones, J. D. G., and Dangl, J. L. 2006. The plant immune system. Nature 444:323-329.

Kang, Z. S., and Li, Z. Q. 1984. Discovery of a normal T. type new pathogenic strain to Lovrin10. Acta Cllegii Septentrionali Occidentali Agric. 4:18-28. (In Chinese)

Keller, T., Damude, H. G., Werner, D., Doerner, P., Dixon, R. A., and Lamb, C. 1998. A plant homolog of the neutrophil NADPH oxidase $\mathrm{gp}^{91 \text { phox }}$ subunit gene encodes a plasma membrane protein with $\mathrm{Ca}^{2+}$ binding motifs. Plant Cell 10:255-266.

Klessig, D. F., Durner, J., Zhou, J. M., Kumar, D., Navarre, D. A., Zhang, S., Shah, J., Wendehenne, D., Du, H., Trifa, Y., Noad, R., Kachroo, P., Pontier, D., Lam, E., and Silva, H. 2000. NO and salicylic acid signaling in plant defense. Proc. Natl. Acad. Sci. U.S.A. 97:8849-8855.

Kopitz, J., André, S., von Reitzenstein, C., Versluis, K., Kaltner, H., Pieters, R. J., Wasano, K., Kuwabara, I., Liu, F. T., Cantz, M., Heck, A. J. R., and Gabius, H. J. 2003. Homodimeric galectin-7 (p53-induced gene 1) is a negative growth regulator for human neuroblastoma cells. Oncogene 22:6277-6288.

Lacomme, C., and Cruz, S. S. 1999. Bax-induced cell death in tobacco is similar to the hypersensitive response. Proc. Natl. Acad. Sci. U.S.A. 96:7956-7961.

Lam, E., Kato, N., and Lawton, M. 2001. Programmed cell death, mitochondria and the plant hypersensitive response. Nature 411:848-853.

Lee, K. S., Chung, E. H., Han, J. H., Sohn, H. D., and Jin, B. R. 2003 cDNA cloning of a defender against apoptotic cell death 1 (DAD1) homologue, responsive to external temperature stimulus from the spider, Araneus ventricosus. Comp. Biochem. Physiol. B: Comp. Biochem. 135:117-123.

Liu, H. M., Liu, T. G., Xu, S. C., Liu, D. Q., and Chen, W. Q. 2006. Inheritance of yellow rust resistance in an elite wheat germplasm Xingzi 9104. Acta Agron. Ainica 32:1742-1745. (In Chinese)

Livak, K. J., and Schmittgen, T. D. 2001. Analysis of relative gene expression data using real-time quantitative PCR and the $2^{-\Delta \Lambda \mathrm{CT}}$ method. Methods 25:402-408.

Ma, J. B., Huang, X. L., Wang, X. J., Chen, X. M., Qu, Z. P., Huang, L. L., and Kang, Z. S. 2009. Identification of expressed genes during compatible interaction between stripe rust (Puccinia striiformis) and wheat using a cDNA library. BMC Genomics 10:586.

Matsumura, H., Nirasawa, S., Kiba, A., Urasaki, N., Saitoh, H., Ito, M., Kawai-Yamada, M., Uchimiya, H., and Terauchi, R. 2003. Overexpression of Bax inhibitor suppresses the fungal elicitor-induced cell death in rice (Oryza sativa L.) cells. Plant J. 33:425-434.

McCabe, P. F., and Leaver, C. J. 2000. Programmed cell death in cell cultures. Plant Mol. Biol. 44:359-368.

McCabe, P. F., Levine, A., Meijer, P. J., Tapon, N. A., and Pennell, R. I. 1997. A programmed cell death pathway activated in carrot cells cultured at low cell density. Plant J. 12:267-280.

Mindrinos, M., Katagiri, F., Yu, G. L., and Ausubel, F. M. 1994. The A. thaliana disease resistance gene RPS 2 encodes a protein containing a nucleotide-binding site and leucine-rich repeats. Cell 78:1089-1099.

Mitsuhar, I., Malik, K.A., Miura, M., and Ohashi, Y. 1999. Animal celldeath suppressors Bcl-x (L) and Ced-9 inhibit cell death in tobacco plants. Curr. Biol. 9:775-778.

Mittapalli, O., and Shukle, R. H. 2008. Molecular characterization and responsive expression of a defender against apoptotic cell death homologue from the Hessian fly, Mayetiola destructor. Comp. Biochem. Physiol. B: Biochem. Mol. Biol. 149:517-523.

Mittler, R., Vanderauwera, S., Gollery, M., and Van Breusegem, F. 2004 Reactive oxygen gene network of plants. Trends Plant Sci. 9:490-498.

Moharikar, S., D'Souza, J. S., and Rao, B. J. 2007. A homologue of the defender against the apoptotic death gene (dadl) in UV-exposed Chlamydomonas cells is downregulated with the onset of programmed cell death. J. Biosci. 32:261-270.

Nakashima, T., Sekiguchi, T., Kuraoka, A., Fukushima, K., Shibata, Y., Komiyama, S., and Nishimoto, T. 1993. Molecular cloning of a human cDNA encoding a novel protein, DAD1, whose defect causes apoptotic cell death in hamster BHK21 cells. Mol. Cell Biol. 13:6367-6374.

Nei, M., and Kumar, S. 2000. Molecular Evolution and Phylogenetics. Oxford University Press, New York.
O’Donnell, K. A., Wentzel, E. A., Zeller, K. I., Dang, C. V., and Mendell, J. T. 2005. c-Myc-regulated microRNAs modulate E2F1 expression. Nature 435:839-843

Orzáez, D., and Granell, A. 1997. The plant homologue of the defender against apoptotic death gene is down-regulated during senescence of flower petals. FEBS (Fed. Eur. Biochem. Soc.) Lett. 404:275-278.

Parlevliet, J. E. 1986. Pleiotropic association of infection frequency and latent period of two barley cultivars partially resistant to barley leaf rust. Euphytica 36:267-272.

Petty, I. T., French, R., Jones, R. W., and Jackson, A. O. 1990. Identification of barley stripe mosaic virus genes involved in viral RNA replication and systemic movement. EMBO (Eur. Mol. Biol. Organ.) J. 9:3453-3457.

Pogue, G. P., Lindbo, J. A., Dawson, W. O., and Turpen, T. H. 1998. Tobamovirus transient expression vectors: Tools for plant biology and high-level expression of foreign proteins in plants. Pages 1-27 in: Plant Molecular Biology Manual. S. B. Gelvin and R. A. Schilperoot, eds. Kluwer Academic Publishers, Dordrecht, The Netherlands.

Pozo-Guisado, E., Merino, J. M., Mulero-Navarro, S., Lorenzo-Benayas, M. J., Centeno, F., Alvarez-Barrientos, A., and Fernandez-Salguero, P. M. 2005. Resveratrol-induced apoptosis in MCF-7 human breast cancer cells involves a caspase-independent mechanism with downregulation of Bcl-2 and NF-kB. Int. J. Cancer 115:74-84.

Qutob, D., Kamoun, S., and Gijzen, M. 2002. Expression of a Phytophthora sojae necrosis-inducing protein occurs during transition from biotrophy to necrotrophy. Plant J. 32:361-373.

Richberg, M. H., Aviv, D. H., and Dangl, J. L. 1998. Dead cells do tell tales. Curr. Opin. Plant Biol. 1:480-485.

Ruf, I. K., Rhyne, P. W., Yang, H., Borza, C., Hutt-Fletcher, L. M., Cleveland, J. L., and Sample, J. T. 1999. Epstein-Barr virus regulates cMYC, apoptosis and tumorigenicity in Burkitt lymphoma. Mol. Cell. Biol. 19:1651-1660.

Scofield, S. R., Huang, L., Brandt, A. S., and Gill, B. S. 2005. Development of a virus-induced gene silencing system for hexaploid wheat and its use in functional analysis of the $\mathrm{Lr} 21$-mediated leaf rust resistance pathway. Plant Physiol. 138:2165-2173.

Skalamera, D., and Heath. M. C. 1998. Changes in the cytoskeleton accompanying infection-induced nuclear movements and the hypersensitive response in plant cells invaded by rust fungi. Plant J. 16:191-200.

Stakman, E. C. 1915. Relation between Puccinia graminis and plants highly resistant to its attack. J. Agric. Res. 4:193-201.

Sugimoto, A., Hozak, R. R., Nakashima, T., Nishimoto, T., and Rothman, J. H. 1995. Dad-1, an endogenous programmed cell death suppressor in Caenorhabditis elegans and vertebrates. EMBO (Eur. Mol. Biol. Organ.) J. 14:4434-4441.

Tanaka, Y., Makishima, T., Sasabe, M., Ichinose, Y., Shiraishi, T., Nishimoto, T., and Yamada, T. 1997. dad-1, A Putative Programmed Cell Death Suppressor Gene in Rice. Plant Cell Physiol. 38:379-383.

Thompson, J. D., Higgins, D. G., and Gibson, T. J. 1994. CLUSTAL W: Improving the sensitivity of progressive multiple sequence alignment through sequence weighting, position-specific gap penalties and weight matrix choice. Nucleic Acids. Res. 11:4673-4680.

Tsusuki, S., Iwami, M., and Sakurai, S. 2001. Ecdysteroid-inducible genes in the programmed cell death during insect metamorphosis. Insect Biochem. Mol. Biol. 31:321-331.

Van Loon, L. C. 1997. Induced resistance in plants and the role of pathogenesis-related proteins. Eur. J. Plant Pathol. 103:753-765.

Van Loon, L. C., and Van Strien, E. A. 1999. The families of pathogenesisrelated proteins, their activities, and comparative analysis of $P R-1$ type proteins. Physiol. Mol. Plant Pathol. 55:85-97.

Wang, C. F., Huang, L. L., Buchenauer, H., Han, Q. M., Zhang, H. C., and Kang, Z. S. 2007. Histochemical studies on the accumulation of reactive oxygen species $\left(\mathrm{O}_{2}{ }^{-}\right.$and $\left.\mathrm{H}_{2} \mathrm{O}_{2}\right)$ in the incompatible and compatible interaction of wheat-Puccinia striiformis f. sp. tritici. Physiol. Mol. Plant Pathol. 71:230-239.

Wang, X. J., Zheng, W. M., Buchenauer, H., Zhao, J., Han, Q. M., Huang, L. L., and Kang, Z. S. 2007. Development of a PCR-based detection of Puccinia striiformis in latent infected wheat leaves. Eur. J. Plant Pathol. 120:241-247.

Wang, X. J., Tang, C. L., Zhang, G., Li, Y. C., Wang, C. F., Liu, B., Qu, Z. P., Zhao, J., Han, Q. M., Huang, L. L., Chen, X. M., and Kang, Z. S. 2009. cDNA-AFLP analysis reveals differential gene expression in compatible interaction of wheat challenged with Puccinia striiformis $\mathrm{f}$. sp. tritici. BMC Genomics 10:289.

Watanabe, N., and Lam, E. 2006. Arabidopsis Bax inhibitor-1 functions as an attenuator of biotic and abiotic types of cell death. Plant J. 45:884-894.

Yoshinaga, K., Arimura, S. I., Hirata, A., Niwa, Y., Yun D. J., Tsutsumi, N., Uchimiya, H., and Kawai-Yamada, M. 2005a. Mammalian Bax initiates plant cell death through organelle destruction. Plant Cell Rep. 24:408 417. 
Yoshinaga, K., Arimura, S. I., Niwa, Y., Tsutsumi, N., Uchimiya, H., and Kawai-Yamada, M. 2005b. Mitochondrial behaviour in the early stages of ROS stress leading to cell death in Arabidopsis thaliana. Ann. Bot. 96:337-342.

Yoshioka, H., Asai, S., Yoshioka, M., and Kobayashi, M. 2009. Molecular mechanisms of generation for nitric oxide and reactive oxygen species, and role of the radical burst in plant immunity. Mol. Cells 28:321-329.

Zhu, L., Song, L. S., Zhang, H., Zhao, J. M., Li, C. H., and Xu, W. 2008. Molecular cloning and responsive expression to injury stimulus of a defender against cell death 1 (DAD1) gene from bay scallops Argopecten irradians. Mol. Biol. Rep. 35:125-132.

\section{AUTHOR-RECOMMENDED INTERNET RESOURCES}

CBS SignalP server: www.cbs.dtu.dk/services/SignalP EMBL-EBI InterProScan database: www.ebi.ac.uk/InterProScan EMBnet TMPRED program:

www.ch.embnet.org/software/TMPRED_form.html

Gene Index Project wheat-specific databases:

compbio.dfci.harvard.edu/tgi/cgi-bin/tgi/gimain.pl?gudb=wheat

Molecular Evolutionary Genetics Analysis Mega4 website, www.megasoftware.net

PBIL Network Protein Sequence Analysis website: npsa-pbil.ibcp.fr Softberry FGENESH software: www.softberry.com 